\author{
Ljubiła Marković, \\ dipl. inž. \\ Mr Predrag Petrović, \\ dipl. inž.
}

\section{SIMULACIONI MODEL ZA ODREDIVANJE UPOTREBNOG KVALITETA KOMPONENATA DIZEL-MOTORA}

\section{Uvod}

Pre razvoja metode ispitivanja potrebno je sistematizovati ulazna ograničenja, sa stanovišta izvođenja ispitivanja, ulaznih mernih parametara, uz zadovoljenje ograničenja vremena i sredstava za realizaciju ispitivanja. Cilj istraživanja je identifikacija metode ispitivanja kao simulacionog modela za određivanje upotrebnog kvaliteta komponenata dizel-motora.

Obrađeno je više modela za ispitivanje tehničkog sistema $u$ funkciji provere njegovih tehničko-funkcionalnih karakteristika, radi provere kriterijuma za njihovu ocenu. U konkretnom slučaju, to znači identifikaciju metode ispitivanja koja će zadovoljiti osnovne zahteve za utvrđivanje upotrebnog kvaliteta automatskog zagrejača.

\section{Osnovna razmatranja}

Ispitivanja $u$ tehnici predstavljaju skup niza postupaka, koji se primenjuju u različitim fazama procesa razvoja, proizvodnje i eksploatacije tehničkog sistema, radi obezbeđivanja objektivnih informacija o kvalitetu tehničkog sistema, njegovih sklopova i delova, a i o uslovima u kojima tehnički sistem radi, odnosno o njegovim radnim opte- rećenjima, okolini i dr. Ispitivanje je jedan od postupaka objektivnog informisanja, a zasnovano je na neposrednom merenju određenih mernih veličina. Zbog svojih osnovanih obeležja ispitivanja imaju poseban značaj $u$ opštem informacionom sistemu proizvođača i korisnika tehničkog sistema.

Sistemi u mašinstvu predstavljaju organizovane skupove elemenata i relacija između njih i njihovih karakteristika, povezanih $\mathrm{u}$ celinu, na način pogodan za obavljanje korisnog rada. Tehnički sistem predstavlja integrisanu celinu, pri čemu integracija podrazumeva međusobnu povezanost i uslovljenost elemenata $i$ njihovih karakteristika. Za funkcionisanje sistema nije dovoljan samo kvalitet elemenata nego i potpuna određenost relacija između njih.

Osnovna postavka ovog rada svodi se na preformulaciju objekta istraživanja, mikrotehničkog sistema u tehnički sistem. Složena konstrukcija automatskog zagrejača, svrstava ga u grupu mikrotehničkih sistema.

Osnovna funkcija automatskog zagrejača je olakšavanje startovanja dizel-motora u uslovima niskih temperatura.

Promenljivost uslova rada i ulaznih parametara koji direktno utiču na 
funkcionisanje automatskog zagrejača i njegove tehničko-funkcionalne karakteristike, daju mu karakter tehničkog sistema sa izuzetno zavisnim ulazno-izlaznim parametrima. Posebnu dimenziju ovim istraživanjima daje identifikacija metode ispitivanja automatskog zagrejača sa stanovišta zadovoljenja ograničenja trajanja ispitivanja i sredstava za izvođenje ispitivanja. To se, pre svega, odnosi na tehničku opremljenost laboratorije za ispitivanje, gde poseban značaj ima optimizacija merno-regulacione opreme, radi ostvarivanja visoke efektivnosti i odgovarajućih optimalnih rešenja automatskih zagrejača. Istraživanja automatskih zagrejača, zasnovana na načelima tehničkih sistema, imaju veliki značaj kao novina $\mathrm{u}$ pristupu ispitivanju ovog tipa, a identifikacija metode ispitivanja je korak ka bržem utvrđivanju njihovog upotrebnog kvaliteta.
Istraživanja tehničko-funkcionalnih karakteristika automatskih zagrejača

Istraživanja tehničko-funkcionalnih karakteristika automatskih zagrejača zasnivaju se na istraživanju efektivnosti sistema u mašinstvu u laboratorijskim i eksploatacionim ispitivanjima. Radna sposobnost sistema predstavlja, na određeni način, meru sposobnosti za obavljanje postavljene funkcije kriterijuma $\mathbf{u}$ datom vremenu, datim uslovima okoline i uticajima poremećaja $u$ procesu rada sistema.

Definicija radne sposobnosti, koja je proistekla iz komponenti efektivnosti tehničkog sistema i njihovih parametara, direktno utiče na nivo i kvalitet izlaznih veličina tehničkog sistema. Pri razmatranju uticaja komponenata efektivnosti na izlazne veličine sistema, treba imati na umu kompleksnost uti-

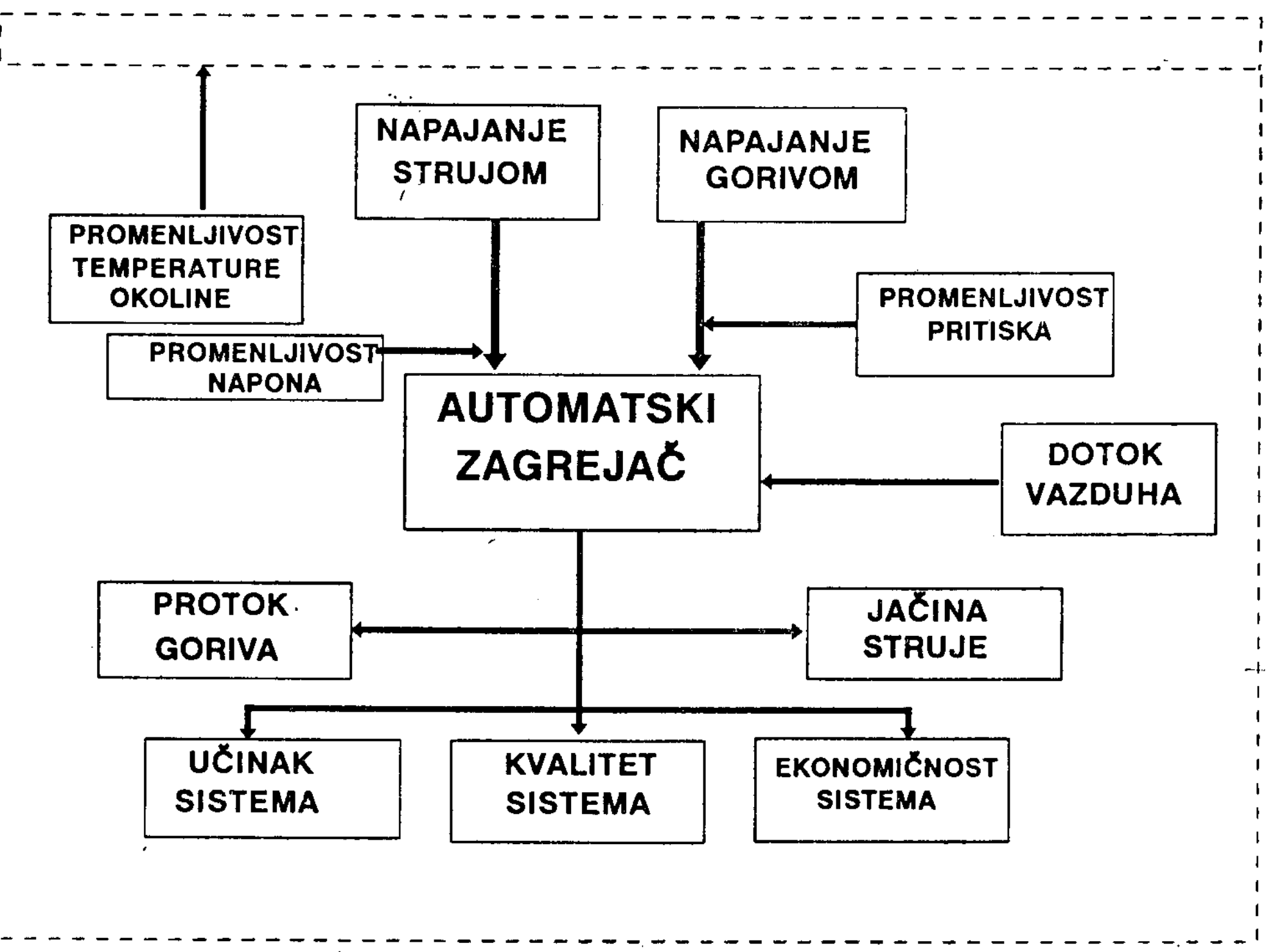

Sl. 1 - Blok šema strukture rada automatskog zagrejača 
caja jedne komponente na izlazne veličine, gde parcijalna posmatranja mogu dovesti do suprotnih zaključaka. Zbog toga treba težiti razvoju kompleksnih pokazatelja uticaja komponenti na efektivnost izlaznih veličina tehničkog sistema. Izlazne veličine i funkcija efektivnosti zavise od mnogo faktora, ali se u kvalitativnom smislu ova zavisnost može svesti na tvrđenje da su izlazne veličine toliko niže koliko su komponente efektivnosti i funkcije efektivnosti u celini niže.

$\mathrm{Na}$ slici 1 prikazana je blok-šema rada automatskog zagrejača i komponente izlaznih tehničko funkcionalnih karakteristika.

Promenljivost ulaznih parametara koji nemaju izraženu zakonitost, i ne mogu se aproksimirati konstantnim vrednostima, otežava definisanje us- lova ispitivanja, pa se moralo razmatrati više metoda ispitivanja, što je, $u$ osnovi, postavka ovog istraživanja.

\section{Program istraživanja}

Analiza rada automatskog zagrejača u uslovima sniženih temperatura okoline nameće potrebu za sistematskim prilazom $u$ izradi programa ispitivanja. $\mathrm{Na}$ slici 2 prikazan je program istraživanja, koje se može sprovesti na motoru i na merno-regulacionoj opremi $u$ laboratoriji.

Analiza mogućnosti ispitivanja automatskih zagrejača na motoru ukazuje na to da se tim ispitivanjima ne može dobiti dovoljno informacija o upotrebnoj vrednosti ispitivanog uzorka. Pri ispitivanju na motoru javljaju se ograničenja koja se ogledaju u nemo-

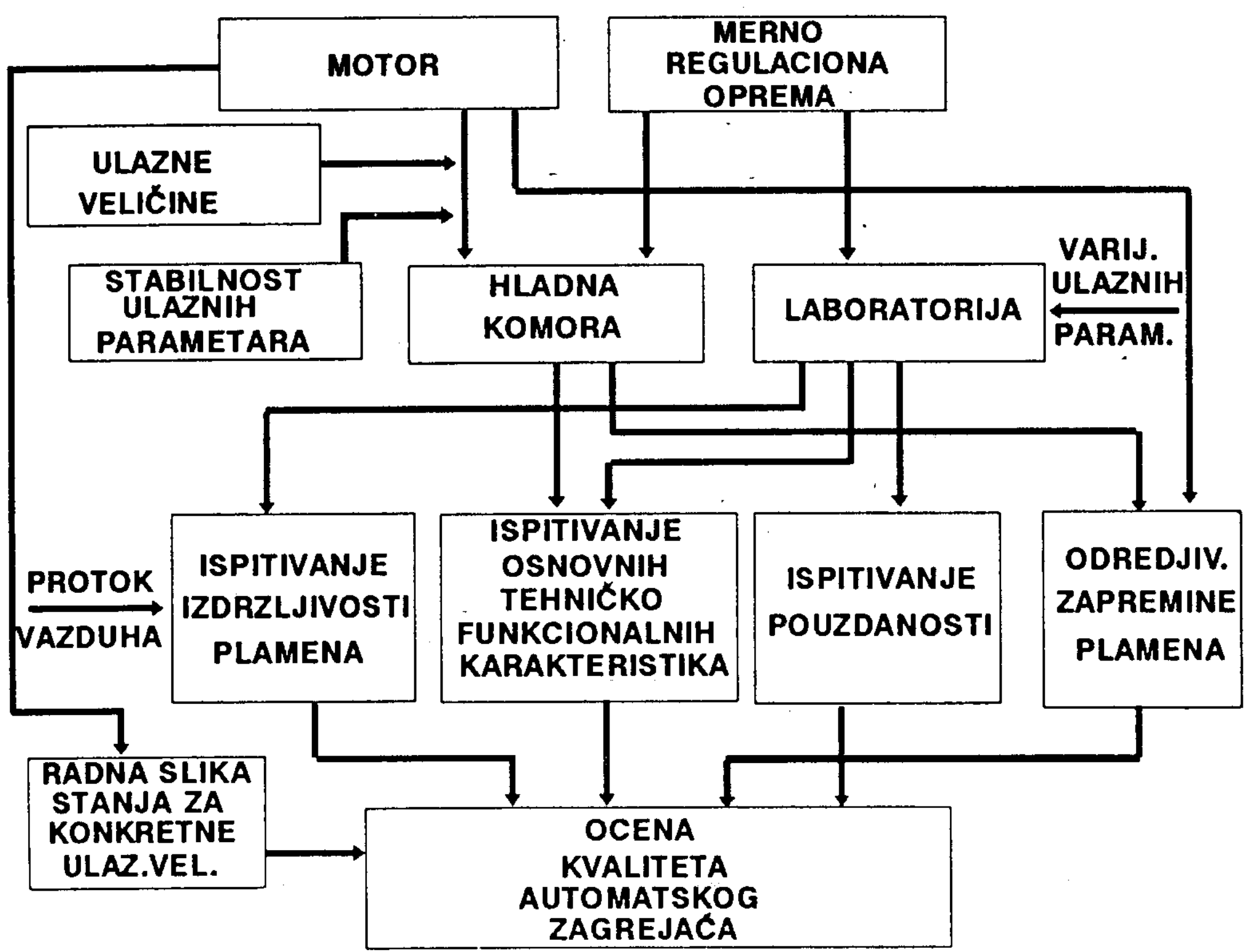

Sl. 2 - Program istraživanja automatskih zagrejača na motoru $i$ merno-regulacionoj opremi 
gućnosti varijacija ulaznih veličina, visoke cene ispitivanja, dužem vremenu pripreme i izvođenja ispitivanja. Navedena ograničenja u razmatranju istraživanja predočavaju istraživačima da na njih ne mogu računati, pa se broj metoda istraživanja smanjuje. Koncepcija izvođenja mernoregulacione instalacije, sa težištem na njenoj fleksibilnosti, daje mogućnost sprovođenja više metoda ispitivanja sa istom opremom. Konačni program istraživanja definisan je na osnovu detaljne analize rada automatskog zagrejača na motoru u uslovima sniženih temperatura, uz aktiviranje ograničavajućih faktora. Na slici 3 prikazana je šema programa ispitivanja.

Program ispitivanja zasniva se na utvrđivanju stvarnih karakteristika sistema i pokazatelja efektivnosti, odno- sno veličina komponenti koje određuju efektivnost, radi poboljšanja kvaliteta projektovanja i izgradnje sistema $i$ kvaliteta eksploatacije.

\section{Rezultati istraživanja}

Prema definisanom programu (slika 3) obavljena su ispitivanja u laboratorijskim uslovima na više uzoraka automatskih zagrejača različitih proizvođača, ali sa identičnim konstrukcijskim rešenjem i primenom različitih materijala za elemente automatskog zagrejača. Cilj ovog rada nije ocena kvaliteta ispitivanih uzoraka automatskih zagrejača, već prikupljanje informacija radi identifikacije metode ispitivanja koja će verodostojno oslikati upotrebni kvalitet ispitivanih uzoraka.

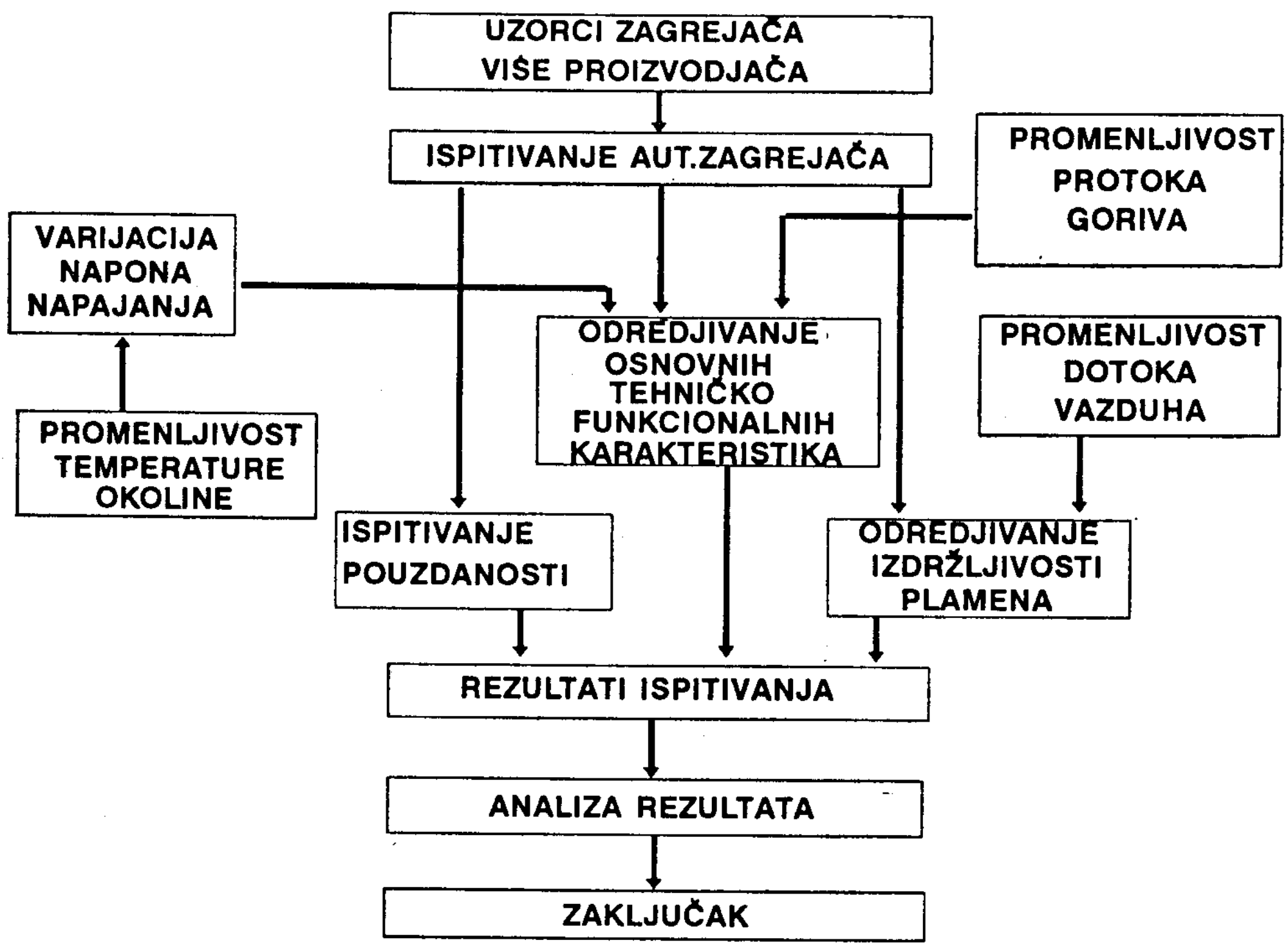

Sl. 3 - Program ispitivanja automatskih zagrejača 
Prikazan je samo deo rezultata ispitivanja pet uzoraka, gde je za osnovni parametar funkcionalnih karakteristika odabran protok goriva.

$\mathrm{Na}$ slici 4 prikazane su vrednosti protoka goriva pet automatskih zagrejača izmerenih tokom sprovođenja više metoda ispitivanja.

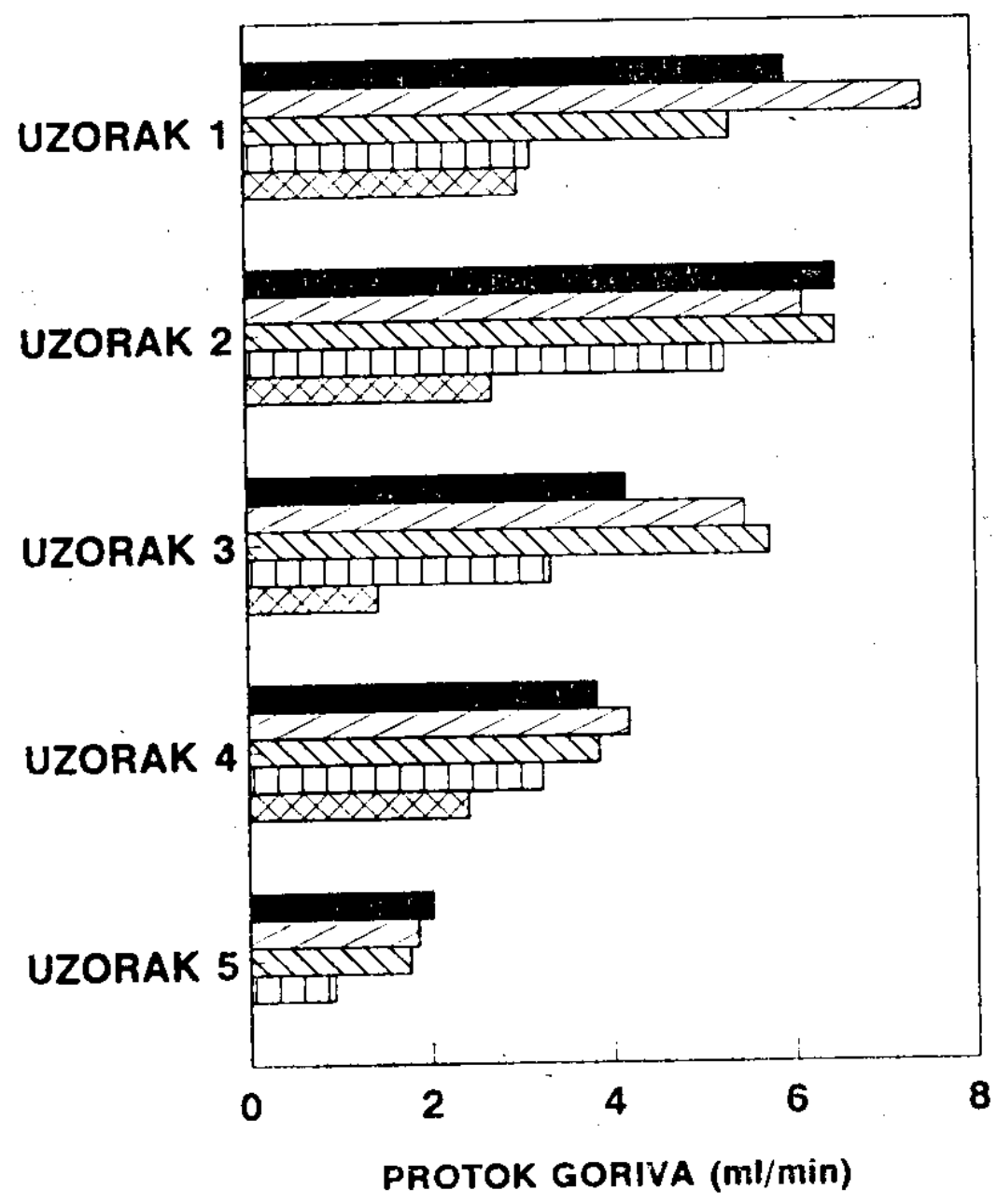

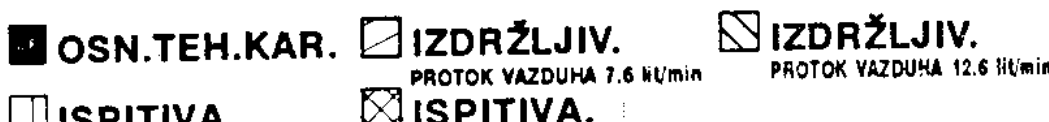
JEMPERATURA KOMOAE -5 C TEMPERATURA KomoRe -10 C

Sl. 4 - Prikaz izmerenih funkcionalnih karakteristika više automatskih zagrejača

\section{Analiza rezultata istraživanja}

Prema rezultatima sprovedenih ispitivanja, kao i analizirane efektivnosti rada automatskog zagrejača, može se identifikovati metoda ispitivanja koja oslikava sva druga sprovedena ispitivanja, a to je ispitivanje osnovnih tehničko-funkcionalnih karakteristika automatskog zagrejača. Identifikacija se zasniva na analizi komponenata efikas- nosti, koja se sastoji od radnog učinka $i$ ispoljene pouzdanosti. Time se potvrđuje da se metodom ispitivanja osnovnih tehničko-funkcionalnih karakteristika oslikava upotrebna vrednost automatskih zagrejača, tj. simulacionim modelom se određuje upotrebni kvalitet ove komponente dizel-motora.

Analiza izmerene vrednosti protoka goriva (slika 4) pokazuje, u zavisnosti od modela ispitivanja, izraženu nestabilnost. To ukazuje da se ne može doneti zaključak o zakonitosti protoka goriva prema modelu ispitivanja. Pad izmerenih vrednosti protoka evidentan je kod ispitivanja u hladnoj komori, ali treba imati u vidu da su uslovi ispitivanja bili promenjeni, tj. ulazni parametri su sa znatno nižim vrednostima (napon na priključcima automatskog zagrejača, pritisak goriva). Prema izmerenim vrednostima protoka goriva najveću efikasnost i radni učinak imaju uzorci 1 i 2 , dok kod ostalih uzoraka ona je znatno niža.

Istraživanja rada automatskog zagrejača dala su veliki broj informacija potrebnih za formiranje kriterijuma za ocenu karakteristika rada automatskog zagrejača. Praćenje karakteristika njihovog rada prema metodama izvođenje ispitivanja i programu ispitivanja ukazuje na kompleksnu međuzavisnost $u$ lazno-izlaznih parametara.

Doprinos istraživanja automatskih zagrejača ogleda se i u potrebi za najužom saradnjom proizvođača i korisnika u području istraživanja, gde identifikacija osnovne metode ispitivanja omogućava međusobnu usklađenost u merno-regulacionoj opremi i u metodi ispitivanja.

Povezivanje proizvođača automatskih zagrejača i korisnika, zasnovano na osnovnoj metodi ispitivanja, pruža niz prednosti u izgradnji tehničkog sistema i njegovom korišćenju, što je bitan preduslov ostvarivanju visokog nivoa efektivnosti i optimalnih konstrukcionih rešenja. 


\section{Zaključak}

Istraživanje efektivnosti sistema $u$ laboratorijskim uslovima radi dobijanja pouzdanih rezultata, zahteva detaljno razrađenu metodologiju programa više metoda ispitivanja. Smanjenje broja metoda ispitivanja, uz ograničenja koja se ogledaju u sredstvima za izvođenje istraživanja, vremenu istraživanja $i$ opremljenosti laboratorije, ukazuje na osnovni metod.

Istraživanja zasnovana na postavci da je automatski zagrejač mikrotehnički sistem sa svojom kompleksnom funkcijom daje veće mogućnosti u oce-

\section{Literatura:}

[1] Zelenović D., Todorović J.: Efektivnost sistema u mašinstvu, Naučna knjiga, Novi Sad-Beograd, 1980. ni kvaliteta i upotrebne vrednosti ispitivanih uzoraka. Ovako koncipirana istraživanja omogućavaju dobijanje velikog broja informacija neophodnih za formiranje kriterijuma za ocenu tehničko-funkcionalnih karakteristika automatskog zagrejača.

Identifikacijom osnovne metode ispitivanja došlo se do simulacionog modela za određivanje upotrebnog kvaliteta komponenata dizel-motora, što omogućava proizvođaču i korisniku da međusobnim povezivanjem daju doprinos $u$ realizaciji tehničkog proizvoda sa velikom upotrebnom vrednošću.

[2] Todorović J.: Ispitivanje motornih vozila, Mašinski fakultet Beograd, Beograd, 1987.

[3] Marković Lj.: Ispitivanje automatskih zagrejača više proizvođača, Izveštaj Instituta IMR-a. 